\title{
Doenças do sistema nervoso central em caprinos e ovinos no semi-árido ${ }^{1}$
}

\author{
Karla M.R. Guedes ${ }^{2}$, Franklin Riet-Correa ${ }^{2}$, Antônio Flávio M. Dantas², Sara V.D. \\ Simões ${ }^{2}$, Eldinê G. Miranda Neto ${ }^{2}$, Verônica M.T. Nobre ${ }^{2}$ e Rosane M.T. Medeiros ${ }^{2}$
}

\begin{abstract}
Guedes K.M.R., Riet-Correa F., Dantas A.F.M., Simões S.V.D., Miranda Neto E.G., Nobre V.M.T. \& Medeiros R.M.T. 2007. [Diseases of the central nervous system in goats and sheep of the semiarid.] Doenças do sistema nervoso central em caprinos e ovinos no semi-árido. Pesquisa Veterinária Brasileira 27(1):29-38. Centro de Saúde e Tecnologia Rural, Universidade Federal de Campina Grande, 58700-000 Patos, PB, Brazil. E-mail: franklin.riet@pesquisador.cnpq.br

The knowledge of the diseases of domestic animals in the different Brazilian regions is important to determine measures for their control and prevention. The objective of this paper is to report the epidemiology, clinical signs and pathology of the diseases of the central nervous system (CNS) of goats and sheep in the Brazilian semiarid, mainly in the state of Paraíba, diagnosed at the Veterinary Hospital of the Federal University of Campina Grande, from January 2000 to May 2006. During the period, 365 cases or outbreaks were diagnosed in goats and 270 in sheep. From these, 63 (9.92\%) were of diseases of the CNS, being 34 (9.31\%) in goats and $29(10.7 \%)$ in sheep. The main diseases were abscesses $(19.04 \%)$, tetanus $(15.9 \%)$, rabies $(9.52 \%)$ poisoning by Ipomoea asarifolia (7.93\%), listeriosis (6.34\%), traumatism (6.34\%), polioencephalomalacia $(4.77 \%)$, pregnancy toxemia $(3.17 \%)$, enzootic ataxia $(3.17 \%)$, and meningitis $(3.17 \%)$. Other diseases diagnosed in only one opportunity $(1.59 \%)$ were intoxications by Crotalaria retusa, Ipomoea carnea, Ipomoea sericophylla and Prosopis juliflora, otitis with encephalitis, malformation, lymphoblastic lymphosarcoma, medulloblastoma, and focal symmetric necrosis. In $6.34 \%$ of the cases diagnosis was unknown.
\end{abstract}

INDEX TERMS: Central nervous system, diseases, goats, sheep, semiarid.

RESUMO.- O conhecimento das doenças dos animais domésticos, nas diferentes regiões do Brasil é importante para determinar formas eficientes de profilaxia e controle. Este trabalho tem como objetivo descrever a epidemiologia, sinais clínicos e patologia das enfermidades do sistema nervoso central (SNC) de caprinos e ovinos, que ocorreram de janeiro de 2000 a maio de 2006 no semi-árido, principalmente do estado da Paraíba. Durante o período, 365 casos ou surtos foram diagnosticados em caprinos e $270 \mathrm{em}$ ovinos. Desses, $63(9,92 \%)$ eram doenças do SNC, sendo 34 (9,31\%) em caprinos e 29 $(10,7 \%)$ em ovinos. As principais enfermidades foram abscessos $(19,04 \%)$, tétano $(15,9 \%)$, raiva $(9,52 \%)$ intoxicação por Ipomoea asarifolia $(7,93 \%)$, listeriose $(6,34 \%)$, trauma $(6,34 \%)$, polioencefalomalacia $(4,77 \%)$,

\footnotetext{
${ }^{1}$ Recebido em 29 de agosto de 2006.

Aceito para publicação em 19 de setembro de 2006.

Parte da dissertação do primeiro autor no Programa de Mestrado em Medicina Veterinária de Pequenos Ruminantes, Centro de Saúde e Tecnologia Rural (CSTR), Universidade Federal de Campina Grande, Paraíba.

2 Hospital Veterinário, CSTR, Universidade Federal de Campina Grande, Campus de Patos, 58700-000 Patos, PB. *Autor para correspondência: franklin.riet@pesquisador.cnpq.br
}

toxemia da prenhez $(3,17 \%)$, ataxia enzoótica $(3,17 \%)$ e meningite $(3,17 \%)$. Outras doenças diagnosti-cadas numa única oportunidade $(1,59 \%)$ foram intoxicações por Crotalaria retusa, Ipomoea camea, Ipomoea sericophylla e Prosopis juliflora, otite com encefalite, malformação, linfossarcoma linfoblás-tico, meduloblastoma e necrose simétrica focal. Em 6,34\% dos casos o diagnóstico foi inconclusivo.

TERMOS DE INDEXAÇÃO: Sistema nervoso central, doenças, caprinos, ovinos, semi-árido.

\section{INTRODUÇÃO}

O conhecimento das doenças dos animais domésticos, nas diferentes regiões do Brasil, é importante para determinar formas eficientes de profilaxia e controle. Para cumprir esse objetivo o Hospital Veterinário do Centro de Saúde e Tecnologia Rural, Universidade Federal de Campina Grande, vem realizando diagnóstico sistemático das doenças de ruminantes e eqüinos na sua área de influência, que abrange principalmente o semi-árido da Paraíba e parte do semi-árido de Pernambuco e Rio Grande do Norte. O objetivo do presente trabalho é descrever a epidemiologia, sinais clínicos e patologia das enfermidades do sistema 
nervoso central (SNC) de caprinos e ovinos, que ocorreram de janeiro de 2000 até maio de 2006 na região mencionada.

\section{MATERIAL E MÉTODOS}

Inicialmente foram identificados nos registros do Laboratório de Patologia Animal (LPA) do Hospital Veterinário (HV), Centro de Saúde e Tecnologia Rural (CSTR) da Universidade Federal de Campina Grande (UFCG) todos os diagnósticos de caprinos e ovinos entre os anos de 2000-2004. As fichas referentes a cada caso de doença do SNC foram revisadas e foram avaliados os dados epidemiológicos (espécie, raça, sexo, idade, procedência e época de ocorrência da doença), evolução, sinais clínicos e achados de necropsia. Cada diagnóstico equivale à ocorrência de doença numa propriedade, podendo se referir tanto a um único animal acometido quanto a um surto. Depois de coletadas as informações foram identificados àqueles casos que possuíam lâminas histológicas, sendo estas então estudadas. Dos casos que possuíam descrição histológica na ficha, mas não se teve acesso às lâminas, foi feita a transcrição dos achados.

Em relação aos casos de raiva, polioencefalomalácia (PEM) e intoxicação por algumas plantas (Ipomoea sericophylla, Crotalaria retusa e Prosopis juliflora) que ocorreram de 2000-2004, foram feitas apenas citações referentes a artigos já publicados sobre essas doenças, sendo descritos aqui apenas os casos não mencionados nesses artigos.

No período de janeiro de 2005 a maio de 2006 foi feito o acompanhamento clínico de todos os casos de caprinos e ovinos que apresentavam sinais neurológicos e foram necropsiados no LPA/HV/CSTR, sendo coletados dados referentes à epidemiologia e histórico da doença. Alguns animais com prognóstico desfavorável ou em estado terminal foram eutanasiados e necropsiados. Outros foram necrop-siados após a morte espontânea. Em todos os casos foi coletado SNC (encéfalo e fragmentos das medulas cervical, torácica e lombar), além de fragmentos de órgãos das cavidades torácica e abdominal, sendo então fixados em formol a $10 \%$ tamponado. Depois de fixados foram feitos cortes de várias porções do SNC incluindo córtex frontal, parietal, temporal e occipital, núcleos da base, tálamo, colículos rostral e caudal, ponte e pedúnculos cerebelares, óbex, cerebelo, medula cervical, torácica e lombar e gânglios do nervo trigêmeo. Nos casos de abscessos medulares foram clivados fragmentos apenas na altura da lesão depois de constatada a inexistência de abscessos em outras áreas do sistema nervoso. Depois de clivados todos os fragmentos foram encaminhados para diafanização e embebição em parafina, sendo posteriormente cortados em seções de $5 \mu \mathrm{m}$ e corados pela hematoxilina e eosina. Cortes da medula de animais suspeitos de ataxia enzoótica foram corados pela técnica de azul rápido de luxol.

Em um caso de abscesso medular o material coletado de um abscesso pulmonar do mesmo animal foi semeado em ágar sangue e submetido a testes bioquímicos para a identificação do agente. Nos materiais suspeitos de raiva foi realizado diagnóstico por imunofluorescência e inoculação em camundongos (Lima et al. 2005a).

\section{RESULTADOS}

De janeiro de 2000 a maio de 2006 foram registrados no LPA/HV 365 diagnósticos de caprinos e 270 de ovinos, em um total de 635 diagnósticos. Desses, $63(9,92 \%)$ correspondiam a alterações do SNC, sendo $34(9,31 \%)$ em caprinos e $29(10,7 \%)$ em ovinos (Quadro 1). As características de cada doença diagnosticada são mencionadas a seguir.

\section{Abscessos}

Foram diagnosticados 12 casos de abscessos afetando o SNC,
Quadro 1. Diagnósticos de doenças do SNC em caprinos e ovinos registrado no LPA/HV no período de janeiro de 2000 a maio de 2006

\begin{tabular}{lcccc}
\hline \multicolumn{1}{c}{ Diagnóstico } & \multicolumn{2}{c}{ Espécie/ $\mathbf{n}^{\circ}$ casos } & Total & $\%$ \\
\cline { 2 - 3 } & Caprinos & Ovinos & & \\
\hline Abscessos no SNC & 03 & 09 & 12 & 19,04 \\
Tétano & 08 & 02 & 10 & 15,9 \\
Raiva & 03 & 03 & 06 & 9,52 \\
Intoxicação por I. asarifolia & 01 & 04 & 05 & 7,93 \\
Diagnósticos sugestivos de listeriose & 03 & 01 & 04 & 6,34 \\
Alterações do SNC devido a trauma & 03 & 01 & 04 & 6,34 \\
Sem diagnóstico & 03 & 01 & 04 & 6,34 \\
PEM & 01 & 02 & 03 & 4,77 \\
Toxemia da prenhez & 02 & - & 02 & 3,17 \\
Ataxia enzoótica & 02 & - & 02 & 3,17 \\
Meningite & 02 & - & 02 & 3,17 \\
Intoxicação por C. retusa & - & 01 & 01 & 1,58 \\
Intoxicação por I. carnea & 01 & - & 01 & 1,58 \\
Intoxicação por I. sericophylla & - & 01 & 01 & 1,58 \\
Intoxicação por P. juliflora & 01 & - & 01 & 1,58 \\
Encefalite devido a otite & - & 01 & 01 & 1,58 \\
Malformação & - & 01 & 01 & 1,58 \\
Linfosarcoma linfoblástico & 01 & - & 01 & 1,58 \\
Meduloblastoma & - & 01 & 01 & 1,58 \\
Necrose simétrica focal & - & 01 & 01 & 1,58 \\
Total & 34 & 29 & 63 & 100 \\
& & & &
\end{tabular}

sendo 4 em caprinos e 8 em ovinos. Dados referentes a esses casos são apresentados no Quadro 2.

Três animais (Casos 1, 3 e 5) apresentaram abscessos no encéfalo. No Caso 1 havia abscessos nas regiões frontal e occipital do hemisfério direito, com sinais clínicos de andar em círculo, debilidade e decúbito. No Caso 3 um abscesso extracerebelar comprimia a porção esquerda do cerebelo e os sinais foram de ataxia, ausência de reflexo palpebral, cegueira parcial, depressão, desvio lateral da cabeça para a esquerda, dificuldade de permanecer em estação, pupilas dilatadas, hiperexcitabilidade, incoordenação, movimentos de rotação da cabeça, nistagmo e ptose da orelha esquerda. No Caso 5 havia um abscesso extrameningeano, sobre o tronco encefálico, que comprimia o cerebelo. Não há relato dos sinais clínicos.

Três casos foram de abscessos extramedulares na região cervical (Casos 2, 8 e 12). Clinicamente os dois primeiros animais apresentaram debilidade dos membros torácicos que progrediu para os membros pélvicos, até permanência em decúbito (Fig.1 e 2). No Caso 12 os sinais clínicos foram de opistótono, letargia, decúbito lateral e emagrecimento.

Em 4 dos casos os abscessos foram encontrados na região das vértebras torácicas, sendo 3 extramedulares (Casos 4, 6 e 11) e um intramedular (Caso 7). Os sinais clínicos foram de dificuldade de locomoção, com incoordenação e paresia dos membros pélvicos, progredindo para decúbito lateral. Tratamento com antiinflamatório e antibiótico foi realizado em 3 animais que tiveram melhora aparente, mas pioraram após alguns dias. O curso clínico variou de 7-20 dias. No animal do Caso 11 foi coletado material para cultura bacteriana, que resultou positivo para Corynebacterium pseudotuberculosis.

Em um caso (Caso 9) o ovino apresentava abscesso retrofaríngeo que através da articulação atlanto-occipital provocava compressão da medula cervical. Os sinais clínicos foram de inco- 
Quadro 2. Dados epidemiológicos referentes aos diagnósticos de abscesso no SNC de caprinos e ovinos no período de janeiro de 2000 a maio de 2006

\begin{tabular}{|c|c|c|c|c|c|c|c|c|}
\hline Caso & Espécie & $\begin{array}{c}\text { Localização } \\
\text { da lesão }\end{array}$ & Idade & Sexo & Raça & Ano & $\begin{array}{c}\text { Época de } \\
\text { ocorrência }\end{array}$ & Município \\
\hline 1 & Ovino & Hemisfério cerebral direito & 60 dias & $\mathrm{M}^{\mathrm{e}}$ & $\mathrm{SRD}^{\mathrm{g}}$ & 2002 & Junho & Patos, PB \\
\hline 2 & Ovino & $\mathrm{C}^{\mathrm{a}} 6-\mathrm{C} 7$ & 1 ano & $\mathrm{M}$ & SRD & 2003 & Maio & Vista Serrana, PB \\
\hline 3 & Ovino & Extracerebelar & $\mathrm{Ni}^{\mathrm{d}}$ & M & Santa Inês & 2003 & Agosto & Patos, PB \\
\hline 4 & Caprino & $\mathrm{T}^{\mathrm{b}} 8$ & 40 dias & $F^{f}$ & SRD & 2004 & Maio & Quixaba, PB \\
\hline 5 & Caprino & Tronco encefálico & 6 anos & M & Moxotó & 2004 & Setembro & Patos, PB \\
\hline 6 & Caprino & $\mathrm{T} 12$ & 4 anos & M & Anglo Nubiano & 2004 & Novembro & São José do Egito, PE \\
\hline 7 & Ovino & $\mathrm{T} 10-\mathrm{T} 11$ & 4 anos & $\mathrm{F}$ & Santa Inês & 2005 & Abril & $\mathrm{Ni}$ \\
\hline 8 & Ovino & $\mathrm{C} 7$ & 2 meses & M & SRD & 2005 & Maio & São José do Bonfim, PB \\
\hline 9 & Ovino & Retrofaríngeo & 3 meses & M & Dorper & 2005 & Julho & Soledade, PB \\
\hline 10 & Ovino & $\mathrm{L}^{\mathrm{C}} 6-\mathrm{L} 7$ & 3 anos & $\mathrm{F}$ & Santa Inês & 2005 & Agosto & $\mathrm{Ni}$ \\
\hline 11 & Ovino & T13-L1 & $\mathrm{Ni}$ & $\mathrm{F}$ & Santa Inês & 2005 & Agosto & $\mathrm{Ni}$ \\
\hline 12 & Caprino & T4-T5 & 4 anos & $\mathrm{F}$ & Pardo Alpino & 2005 & Setembro & $\mathrm{Ni}$ \\
\hline
\end{tabular}

${ }^{\mathrm{a}} \mathrm{C}=$ vértebra cervical, ${ }^{\mathrm{b}} \mathrm{T}=$ vértebra torácica, ${ }^{\mathrm{C}} \mathrm{L}=$ vértebra lombar, ${ }^{\mathrm{d}} \mathrm{Ni}=$ não informado, ${ }^{\mathrm{e}} \mathrm{M}=$ macho, ${ }^{\mathrm{f}} \mathrm{F}=$ fêmea, ${ }^{\mathrm{g}} \mathrm{SRD}=$ sem raça definida.

ordenação, apatia, desvio lateral da cabeça e pescoço, bruxismo e decúbito permanente. $\mathrm{O}$ animal foi tratado por 4 dias com antiinflamatório, antibiótico e vitamina $\mathrm{B}_{1}$, mas não apresentou melhora.

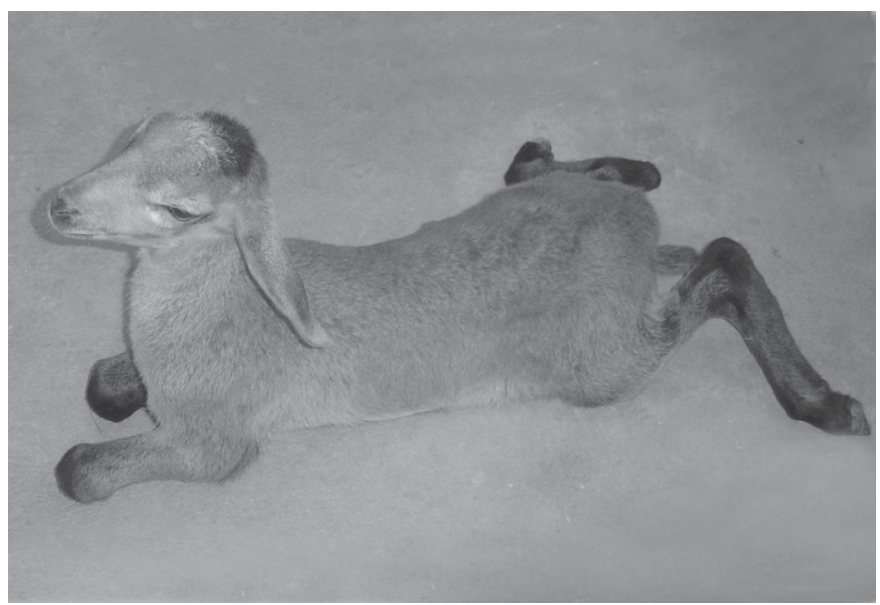

Fig.1. Ovino com paralisia dos 4 membros em face de abscesso na coluna vertebral cervical.

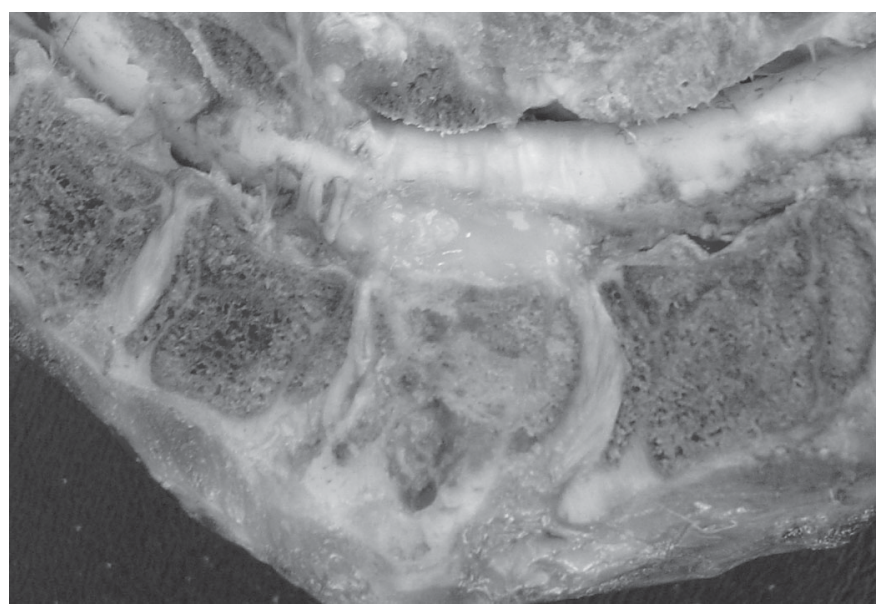

Fig.2. Medula e vértebras C5-T1, com abscesso extramedular à altura da $7^{a}$ vértebra cervical do ovino da figura anterior.
Um ovino apresentou abscesso extramedular na região lombar (Caso 10), com sinal clínico de incoordenação dos membros pélvicos por 30 dias.

Em 8 dos 12 animais (Casos 1, 3, 5, 6, 8, 9, 11 e 12) havia abscessos em outras partes do corpo, principalmente nos pulmões, linfonodos mediastínicos e fígado. Em um ovino (Caso 1) havia abscesso na veia umbilical.

Nos Casos em que foi feito estudo histológico (Casos 7, $10 \mathrm{e}$ 11), as lesões eram variáveis, observando-se acentuado infiltrado neutrofílico, com necrose e colônias bacterianas intralesionais, compressão dos funículos ventrais e laterais, malácia da substância branca e formação de esferóides axonais e manguitos perivasculares neutrofílicos e histiocíticos.

\section{Tétano}

Foram diagnosticados 10 casos de tétano, sendo $8 \mathrm{em}$ caprinos e 2 em ovinos. Os dados epidemiológicos referentes a esses casos podem ser encontrados no Quadro 3.

A provável porta de entrada de Clostridium tetani foi sugerida em 5 dos 10 casos diagnosticados. Em 3 casos (Casos 1, 4 e 5) os sinais clínicos surgiram após realização de castração, e ao exame macroscópico observou-se secreção purulenta no saco escrotal. No Caso 7, de um lote de 60 animais que haviam sido submetidos a descorna, dois haviam morrido 24 horas depois de surgirem os primeiros sinais clínicos e dois estavam em tratamento na propriedade, não se tendo informação se sobreviveram. Os animais doentes desenvolveram sinais 10 dias após a descorna e apresentavam necrose no local da ferida. 0 Caso 9 refere-se a uma ovelha que havia parido 8 dias antes de apresentar sinais clínicos de tétano, e logo após o parto apresentara prolapso vaginal, que foi corrigido cirurgicamente. Nos demais casos não houve informação sobre a provável porta de entrada do agente.

Os sinais clínicos variaram, incluindo trismo mandibular, andar rígido, decúbito lateral, orelhas eretas, tetania, rigidez e tremores musculares, opistótono, nistagmo, espasticidade, estrabismo, prolapso da terceira pálpebra e cauda estendida. Em nenhum dos casos foram encontradas lesões macroscópicas ou histológicas de significado no SNC.

Nenhum caprino ou ovino recebido no HV com sinais de tétano recuperou-se. 
Quadro 3. Dados epidemiológicos referentes aos diagnósticos de tétano no LPA/HV no período de janeiro de 2000 a maio de 2006

\begin{tabular}{|c|c|c|c|c|c|c|c|}
\hline Surto & Espécie & Idade & Sexo & Raça & Ano & $\begin{array}{c}\text { Época de } \\
\text { ocorrência }\end{array}$ & Município \\
\hline 1 & Caprino & 6 meses & $M^{b}$ & Moxotó & 2000 & Junho & Patos, PB \\
\hline 2 & Caprino & $\mathrm{Ni}^{\mathrm{a}}$ & $\mathrm{F}^{\mathrm{C}}$ & $\mathrm{SRD}^{\mathrm{d}}$ & 2000 & Novembro & Patos, PB \\
\hline 3 & Caprino & 4 anos & $\mathrm{F}$ & $\mathrm{Ni}$ & 2001 & Fevereiro & Serra Branca, PB \\
\hline 4 & Ovino & 8 meses & M & SRD & 2001 & Abril & São Mamede, PB \\
\hline 5 & Caprino & 1 ano & M & SRD & 2002 & Junho & Patos, PB \\
\hline 6 & Caprino & 6 meses & M & SRD & 2002 & Outubro & $\mathrm{Ni}$ \\
\hline 7 & Caprino & 40 dias & $\mathrm{F}$ & Saanen & 2002 & Outubro & Bananeiras, PB \\
\hline 8 & Caprino & 3 anos & $\mathrm{F}$ & SRD & 2004 & Maio & Quixaba, PB \\
\hline 9 & Ovino & $\mathrm{Ni}$ & $\mathrm{F}$ & SRD & 2005 & Outubro & Patos, PB \\
\hline 10 & Caprino & 10 dias & M & SRD & 2006 & Maio & Patos, PB \\
\hline
\end{tabular}

${ }^{\mathrm{a}} \mathrm{Ni}=$ não informado; ${ }^{\mathrm{b}} \mathrm{M}=$ macho; ${ }^{\mathrm{c}} \mathrm{F}=$ fềmea; ${ }^{\mathrm{d}} \mathrm{SRD}=$ sem raça definida.

\section{Raiva}

Dos 6 surtos de raiva diagnosticados em caprinos e ovinos, 5 ocorreram no período de janeiro de 2000 a dezembro de 2004 e 4 foram descritos por Lima et al. (2005a). Dois casos que não foram incluídos nesse trabalho são descritos a seguir. O primeiro ocorreu em um ovino adulto, macho, da raça Santa Inês, em março de 2004, no município de São José de Espinharas, na Paraíba, e o segundo em novembro de 2005, em um caprino mestiço de Boer, macho, com 2 anos de idade, proveniente do município de São Mamede, Paraíba. A doença teve um curso clínico de 5 dias nos dois casos, e os sinais encontrados variaram. Foi observada depressão, reflexo palpebral diminuído, agressividade, vocalização, salivação, incoordenação e paralisia flácida dos membros pélvicos, paralisia espástica dos membros torácicos, movimentos de pedalagem e relaxamento do esfincter anal.

Macroscopicamente não havia lesões significativas, mas no exame histológico observou-se, no primeiro caso, meningite não supurativa, difusa, discreta, com mielite linfocitária, principalmente na região da medula torácica e presença de corpúsculos de Negri nos neurônios da substância cinzenta medular. No segundo caso havia discretos manguitos linfocitários na zona medular do cerebelo e corpúsculos de Negri nas células de Purkinje. No tronco encefálico havia corpúsculos de Negri nos neurônios do núcleo dorsal do nervo vago. $\mathrm{O}$ exame de IFD foi negativo no primeiro caso e positivo no segundo.

\section{Intoxicação por Ipomoea asarifolia (salsa)}

Cinco surtos de intoxicação por I. asarifolia foram diagnosticados, sendo 1 em caprinos e 4 em ovinos. Os dados referentes a esses surtos encontram-se no Quadro 4.
Em todos os surtos, os animais acometidos tinham menos de 4 meses de idade, com exceção de um reprodutor no Surto 3 , que apresentou sinais nervosos, mas se recuperou. Todos os animais foram trazidos ao LPA/HV com história de sinais nervosos após ingestão da planta, principalmente no período de estiagem, quando há pouca disponibilidade de forragem e a salsa ainda está verde. Em apenas 2 surtos não havia história de ocorrência anterior da doença (Surtos 1 e 4). No Surto 5 foram acometidos 26 animais de um rebanho de 600 ovinos. Havia relato da doença em anos anteriores, sempre em animais com menos de 2 meses e os episódios duravam aproximadamente 1 mês, sempre na época de estiagem. Na maioria dos surtos registrados no LPA os sinais clínicos duravam de 7-10 dias, até que os animais morriam ou eram eutanasiados por não apresentarem melhora no quadro clínico.

Os sinais clínicos em todos os animais caracterizavam-se por tremores musculares que podiam ser generalizados ou somente da cabeça e se agravavam quando os animais eram movimentados, hiperexcitabilidade, midríase, opistótono, estrabismo, dismetria, severa incoordenação e quedas. Em aproximadamente uma semana do início dos sinais alguns animais ficavam em decúbito lateral, urinando e defecando com freqüiência. Quando colocados em estação não conseguiam permanecer em pé e andar, voltando para o decúbito e apresentando tremores musculares.

Não havia lesões macroscópicas significantes. Os animais dos Surtos 2 e 3 não apresentavam lesões histológicas do sistema nervoso central. No ovino do Surto 1 havia vacúolos na camada granular do cerebelo (Fig.3) com raros esferóides axonais e moderado número de células de Purkinje contendo vacúolos

Quadro 4. Dados dos surtos de intoxicação por Ipomoea asarifolia diagnosticados no LPA no período de janeiro de 2000 a maio de 2006

\begin{tabular}{|c|c|c|c|c|c|c|c|c|}
\hline Surto & Espécie & Idade & $\begin{array}{c}\text { № animais } \\
\text { acometidos }\end{array}$ & Sexo & Raça & Ano & $\begin{array}{c}\text { Época de } \\
\text { ocorrência }\end{array}$ & Município \\
\hline 1 & Ovino & 1 mês & 01 & $\mathrm{~F}^{\mathrm{a}}$ & SRD & 2001 & Junho & São Sebastião do Umbuzeiro, PB \\
\hline 2 & Caprino & 2-3 meses & 07 & $\mathrm{~F}$ & $\mathrm{Ni}^{\mathrm{C}}$ & 2001 & Outubro & Condado, PB \\
\hline 3 & Ovino & 3-4 meses & 15 & $\mathrm{M}^{\mathrm{b}} / \mathrm{F}$ & $\mathrm{SRD}^{\mathrm{d}}$ & 2003 & Setembro & Santa Terezinha, PB \\
\hline 4 & Ovino & 2 meses & 01 & M & SRD & 2003 & Novembro & Patos, PB \\
\hline 5 & Ovino & 2-3 meses & 26 & M & Santa Inês & 2004 & Agosto & São Mamede, PB \\
\hline
\end{tabular}



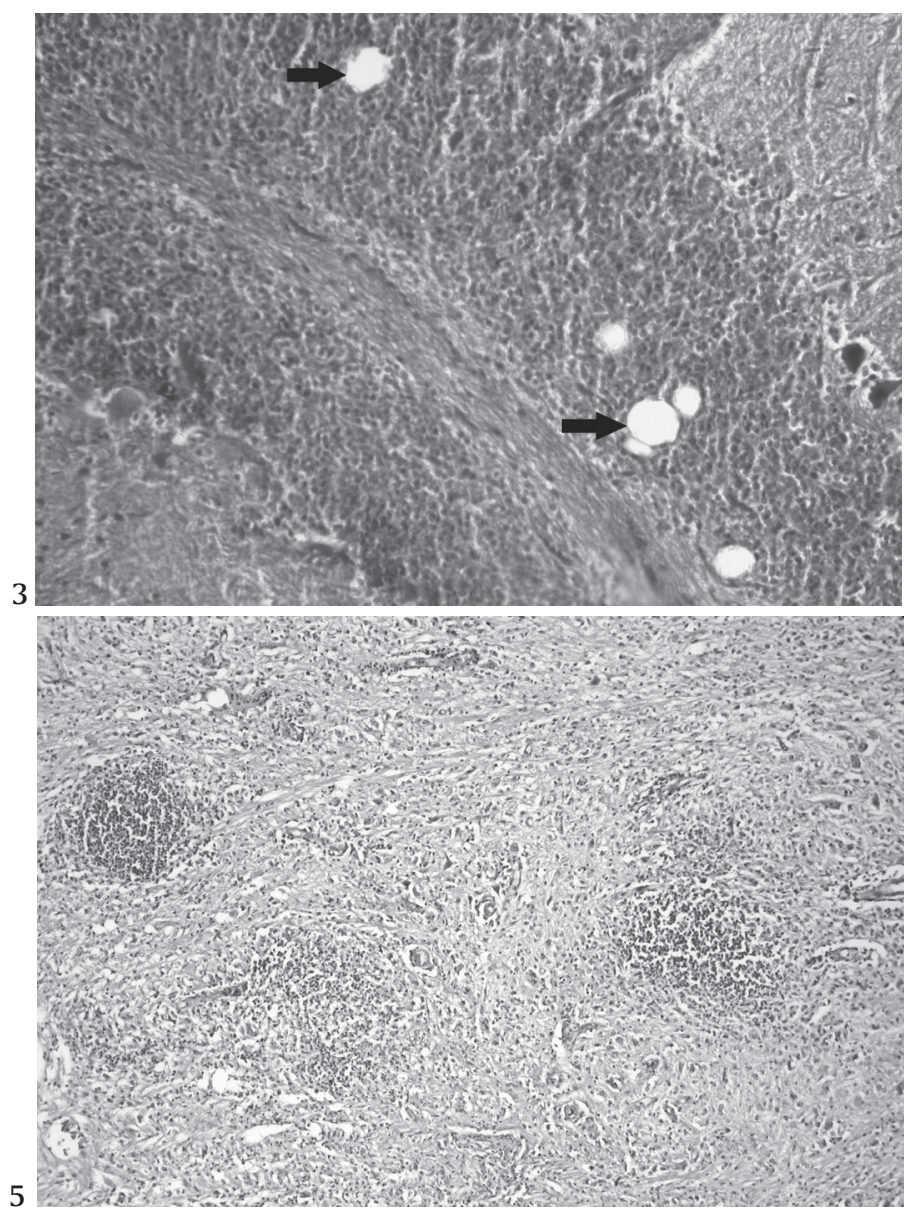

intracitoplasmáticos. No ovino do Surto 4 havia uma quantidade discreta de esferóides axonais na camada granular do cerebelo. No ovino que foi necropsiado no Surto 5 havia vacuolização das células de Purkinje e também numerosos esferóides na camada granular do cerebelo (Fig 4).

\section{Listeriose}

Quatro animais apresentaram lesões histológicas características da listeriose, sendo 1 ovino e 3 caprinos (Quadro 5).

Em todos os casos os sinais clínicos iniciavam subitamente e incluíam desvio lateral da cabeça e pescoço, nistagmo, andar em círculos, paralisia da mandíbula e língua, estrabismo, reflexo pupilar diminuído, decúbito lateral e movimentos de pedalagem alternados com espasticidade dos membros. No

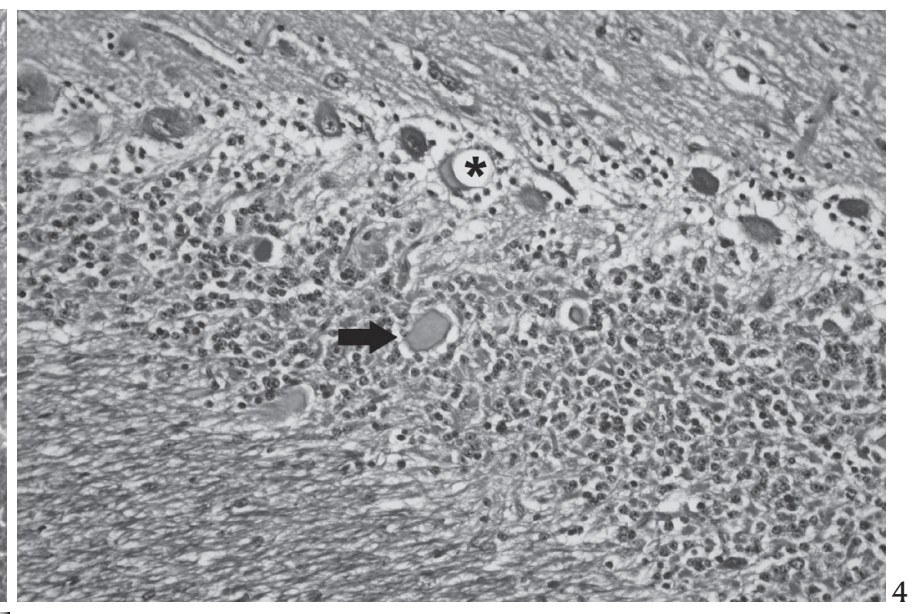

Fig.3. Vacúolos (setas) na camada granular do cerebelo de ovino do Surto 1, que devem ter se formado em consequiência da degeneração e do posterior desaparecimento do axônio (compare Fig. 4). HE, obj.10.

Fig.4. Vacuolização de células de Purkinje (asterisco) e esferóides axonais (seta) na camada granular do cerebelo de ovino do Surto 5. HE, obj. 20.

Fig.5. Microabscessos multifocais no tronco encefálico de caprino do Surto 2. HE, obj.10.

Surto 2, seis animais de um rebanho de 300 morreram após apresentarem sinais semelhantes.

Em um animal (Caso 1) foi observado aumento do volume e aspecto esponjoso na região dos pedúnculos cerebelares esquerdos. Os demais não apresentavam lesões macroscópicas significativas.

Histologicamente as lesões eram semelhantes em todos os casos, geralmente caracterizadas por presença de microabscessos na ponte, pedúnculos cerebelares (Fig.5) e substância branca cerebelar, infiltrado inflamatório neutrofilico no neurópilo e ao redor de vasos e infiltrado mononuclear nas meninges e ao redor dos vasos. Nas várias porções do tronco encefálico as lesões se encontravam geralmente à altura do trato espinhal do nervo trigêmeo, ou entre a raiz do nervo facial e corpo trapezói-de. No Caso 4 se via lesão semelhante no gânglio do nervo trigêmeo.

\section{Traumatismo}

Foram diagnosticados 4 casos de alteração do SNC devido a lesão provocada por trauma, sendo 3 devidos a trauma medular e 1 de trauma cerebral.

Quadro 5. Casos que apresentaram sinais clínicos e lesões histológicas sugestivas de listeriose no período de janeiro de 2000 a maio de 2006 no LPA/HV

\begin{tabular}{|c|c|c|c|c|c|c|c|}
\hline Caso & Espécie & Idade & Sexo & Raça & Ano & $\begin{array}{c}\text { Época de } \\
\text { ocorrência }\end{array}$ & Município \\
\hline 1 & Ovino & 6 meses & $\mathrm{F}^{\mathrm{a}}$ & Santa Inês & 2002 & Abril & Patos, PB \\
\hline 2 & Caprino & 1 ano & $M^{b}$ & Anglo Nubiano & 2005 & Maio & São José de Espinharas, PB \\
\hline 3 & Caprino & 18 meses & $\mathrm{F}$ & Pardo Alpino & 2005 & Julho & Caturité de Boqueirão, PB \\
\hline 4 & Caprino & Adulto & $\mathrm{F}$ & $\mathrm{SRD}^{\mathrm{C}}$ & 2006 & Maio & São José de Espinharas, PB \\
\hline
\end{tabular}


Em dois caprinos machos, um de 2 meses de idade e outro de 11 meses, foram observados sinais clínicos de flacidez dos membros torácicos e espasticidade dos membros pélvicos, reflexo de flexão dos membros torácicos ausente e dos pélvicos aumentados, incoordenação, reflexo do panículo na região da cernelha ausente, priapismo, tenesmo e ranger de dentes. Na necropsia observou-se fratura da sexta vértebra cervical no primeiro animal e da sétima vértebra cervical no segundo. Um terceiro caprino, fêmea, de 20 dias de idade foi trazida ao HV por apresentar paralisia dos membros pélvicos, sendo realizado o diagnóstico de trauma medular, mas não havia descrição do local da lesão.

O quarto caso foi observado em um ovino macho de aproximadamente 4 anos de idade que apresentava paresia dos membros torácicos e sensibilidade à percussão nos seios nasais e frontais. $\mathrm{O}$ animal foi visto anteriormente brigando com outro macho do rebanho. $\mathrm{O}$ exame macroscópico revelou hemorragia nos seios nasais e do lobo direito do encéfalo.

\section{Polioencefalomalacia (PEM)}

Foram diagnosticados, de janeiro de 2000 a maio de 2006, três surtos de PEM em pequenos ruminantes, sendo 2 em ovinos e 1 em caprinos. 0 surto em caprinos e um dos surtos em ovinos foi descrito por Lima et al. (2005b). O segundo surto de PEM ocorreu em maio de 2005, em um rebanho de 300 ovinos da raça Santa Inês, dos quais adoeceram e morreram 9 animais. Um dos ovinos afetados foi encaminhado ao HV e apresentava cegueira, opistótono, andar cambaleante e ataxia. No mesmo período 6 outros animais apresentavam os mesmos sinais e foram tratados com vitamina $\mathrm{B}_{1}$, mas acabaram morrendo. Quinze dias antes outros 2 ovinos haviam morrido com os mesmos sinais clínicos. O rebanho recebia como alimentação uma ração formulada com $30 \%$ de milho, $30 \%$ de sorgo, $20 \%$ de torta de babaçu e feno de capim Tifton (Cynodon dactylon). A torta de babaçu tinha sido incorporada à ração 5 dias antes do início do surto e segundo o proprietário as mortes pararam logo depois que ela foi retirada da dieta. No exame macroscópico observaram-se, no encéfalo, áreas amareladas no córtex frontal, com cavitações entre a substância branca e a cinzenta. Na histologia observaram-se grandes áreas de necrose cortical, caracterizadas por palidez difusa da substância cinzenta, eosinofilia de neurônios, hiperplasia endotelial, e algumas áreas de cavitação, com células gitter ao redor. Em outras áreas a necrose era laminar, com aumento do espaço perivascular e perineuronal. Havia discreta meningite eosinofílica. No cerebelo, na região do nódulo, havia necrose tanto da substância branca quanto da cinzenta, com comprometimento da camada granular, das células de Purkinje e da camada molecular.

\section{Toxemia da prenhez}

Dois surtos de toxemia da prenhez foram diagnosticados durante o período.

O primeiro aconteceu no município de São Mamede, Paraíba, em agosto de 2003, em um rebanho de 80 cabras da raça Anglo Nubiana e cruzas, das quais havia 3 afetadas, de aproximadamente 3 anos de idade. Os animais eram criados soltos no pasto, mas devido à estiagem e escassez de forragem foram confinados e começaram a receber silagem de capim elefante (Pennisetum purpureum) e concentrado a base de trigo e milho. As cabras não estavam gordas podendo a maioria ser classificada como de escore corporal 2,0-2,5 (em uma escala de 1-5) (Ribeiro 1997). Os casos começaram 5 dias após a mudança na alimentação. As cabras afetadas, que estavam em gestação, começaram a se isolar do rebanho, ficaram deprimidas, e uma delas começou a apresentar desvio lateral da cabeça para a direita e andar cambaleante. Apresentavam ainda incoordenação, espasticidade dos membros pélvicos e bruxismo. A suspeita clínica inicial era de PEM, por isso os animais foram tratados com vitamina $B_{1}$, dexametazona e antitóxico. No dia seguinte a cabra que apresentou desvio lateral da cabeça morreu e na necropsia observou-se fígado aumentado de tamanho e amarelado, além de edema pulmonar e útero contendo 2 fetos, no último mês de gestação. $O$ exame de urina revelou presença de corpos cetônicos acima de $80 \mathrm{mg} / \mathrm{dl}$, quando valores de $10-100 \mathrm{mg} / \mathrm{dl}$ são considerados elevados (Smith \& Sherman 1994). No estudo histológico observou-se fígado com degeneração gordurosa, cerebelo com uma grande quantidade de pequenos vasos congestos, principalmente na zona medular, rim e coração congestos. Segundo o proprietário as outras duas cabras pariram 1 semana depois e morreram após 3 dias.

O segundo caso diz respeito a um caprino, fêmea, SRD, de 5 anos de idade, proveniente do município de Patos, Paraíba, e levada ao LPA em fevereiro de 2005. A proprietária informou que $o$ animal fora adquirido há 5 dias e que estava sem apetite. Apresentava dificuldade de permanecer em estação e de andar, estrabismo e movimentos de pedalagem. No exame de urina os corpos cetônicos estavam em $80 \mathrm{mg} / \mathrm{dl}$. $\mathrm{O}$ animal estava no terço final da gestação e morreu após atendimento clínico. Na necropsia, realizada no outro dia, a carcaça estava autolisada, mas o fígado estava amarelado.

\section{Ataxia enzoótica}

Dois surtos da doença foram diagnosticados pelo LPA/HV, sendo todos em caprinos.

O primeiro ocorreu em um rebanho do município de Patos, Paraíba, em junho de 2000. Um caprino de 30 dias de idade foi levado ao HV apresentando paralisia flácida dos quatro membros e discretos tremores de cabeça. Nesta fazenda nasceram 15 cabritos entre os meses de maio e junho, e todos morreram com sinais clínicos semelhantes. No animal que foi necropsiado não se observaram lesões macroscópicas significativas. No estudo histológico foi observada degeneração Walleriana da substância branca da medula, principalmente nos funículos ventrais. Neurônios da medula, e em menor freqüência do tronco encefálico, estavam eosinofílicos, com cromatólise difusa do pericário e, algumas vezes, com o núcleo marginalizado. A coloração de azul rápido de luxol evidenciou a perda de mielina na substância branca nos cortes de medula (Fig. 6). Duas amostras de soro de cabritos afetados foram enviadas para o Professor Enrico Ortolani, da Universidade de São Paulo, para determinação dos níveis séricos de $\mathrm{Cu}$. Os teores de Cu nas duas amostras foram de 1,61 e 1,29 $\mu \mathrm{mol} / \mathrm{L}$, abaixo dos valores normais, que são de 9,24-23,6 $\mu \mathrm{mol} / \mathrm{L}$ (Smith \& Sherman 1994).

No segundo surto, no município de São Sebastião do Umbuzeiro, Paraíba, foram afetados 4 caprinos em um rebanho 


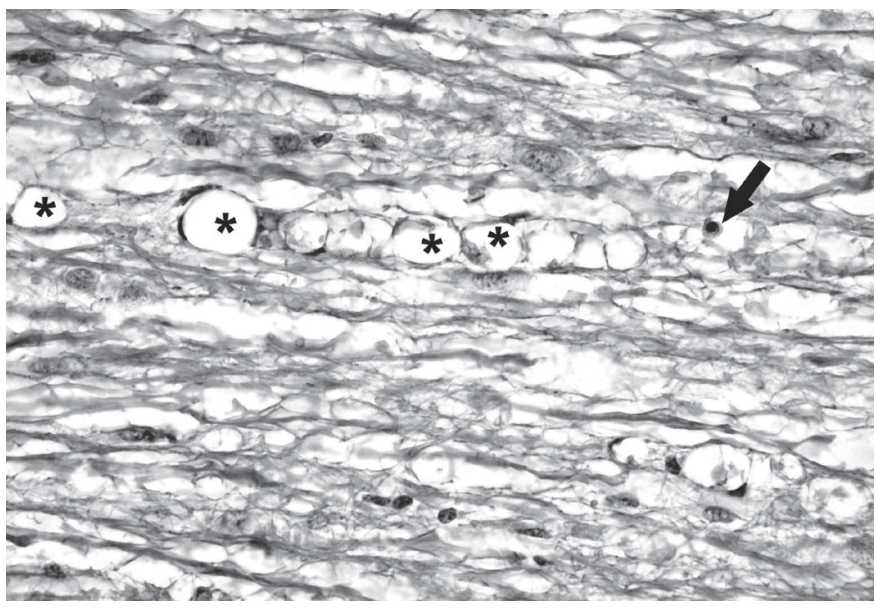

Fig.6. Degeneração Walleriana, caracterizada por vacúolos ordenados em forma de cadeia (asteriscos) com presença de macrófagos (seta), na medula de caprino. Azul Rápido de Luxol, obj. 20.

de 33 fềmeas com 7 meses a 1 ano de idade que estavam numa área de capim buffel (Cenchrus ciliaris). $O$ primeiro caso da doença aconteceu no final de 2005. O animal apresentou paresia dos membros pélvicos, teve uma melhora aparente, mas acabou morrendo. No ano de 2006 foram afetadas e morreram mais duas fêmeas da mesma faixa etária e outra foi levada ao HV por apresentar debilidade dos membros pélvicos, com flexão das articulações tarso-metatarsianas e quedas quando movimentado. Aproximadamente dois dias após ser internado o animal apresentou arrastar das pinças dianteiras, além de bruxismo, diminuição do reflexo pupilar, ausência do reflexo anal, ausência do reflexo da deglutição e secreção nasal purulenta. No início do quadro clínico o animal apresentava ainda estridor traqueal, que desapareceu após alguns dias, bradipnéia e arritmia cardíaca. Na necropsia observou-se atrofia dos músculos da coxa, e pulmão com áreas de consolidação do lobo apical direito. Histologicamente havia na medula lesões semelhantes às descritas no primeiro surto.

\section{Meningite}

Em um caprino com 3 semanas de idade, do município de São Mamede, Paraíba, foi observado um caso de meningite supurativa em consequiência de infecção neonatal. $O$ animal apresentava, também, onfaloflebite, bexiga urinária com conteúdo purulento, pericardite fibrinosa e edema pulmonar. Outro caso de meningoencefalomielite supurativa, em conseqüência de descorna, foi observado num caprino adulto do município de Patos.

\section{Intoxicação por Ipomoea carnea subsp. fistulosa (algodão-bravo)}

Um surto de intoxicação por algodão-bravo ocorreu em uma propriedade com um rebanho de 172 caprinos no município de Ouro Velho, Paraíba, dos quais adoeceram 25 e morreram nove. A doença ocorreu em dezembro de 2001 e os caprinos haviam sido adquiridos em janeiro do mesmo ano. Anteriormente só havia ovinos e bovinos na propriedade. Na fazenda havia uma área de aproximadamente 6 ha no leito de um açude invadida pela planta, que fora introduzida 20 anos antes para combater a erosão. Os caprinos começaram a ingerir a planta na época seca, mas após as chuvas, quando iniciou a brotação, mostraram avidez pela mesma, ingerindo-a em grandes quantidades.

Os sinais clínicos apresentados foram ataxia, hipermetria, paresia espástica, com andar rígido principalmente dos membros pélvicos, nistagmo e tremores laterais da cabeça. Os sinais se agravavam quando os animais eram movimentados ou assustados, observando-se perda de equilíbrio e quedas. Alguns animais se recuperaram, mas 7 permaneceram com os sinais clínicos após serem retirados da área invadida pela planta. Não foram encontradas lesões macroscópicas significativas em um caprino com sinais clínicos que havia permanecido doente por aproximadamente 30 dias. No exame histológico foi observado, no cerebelo, discreto número de esferóides axonais na camada granular e numerosos esferóides axonais com marcada degeneração Walleriana e status spongiosus na zona medular do cerebelo. Nos neurônios da medula cervical, torácica e lombar foi vista moderada vacuolização intracitoplasmática fina, principalmente nos neurônios dos cornos ventrais. Na medula torácica havia ainda discretos esferóides axonais tanto na porção medial dos cornos ventrais, quanto nos funículos dorsais.

\section{Outras plantas tóxicas}

Os surtos de intoxicação por Ipomoea sericophylla e Prosopis juliflora observados durante o período foram relatados por Barbosa et al. (2006) e Lima et al. (2004), respectivamente. Surtos de encefalopatia hepática secundária a intoxicação crônica por Crotalaria retusa foram descritos por Dantas et al. (2004).

\section{Otite com encefalite}

Um ovino, fêmea, com 3 anos de idade, foi levado ao HV por estar há 4 dias em decúbito esternal, sem conseguir se levantar nem permanecer em estação. Durante o exame clínico o ovino apresentava ainda nistagmo bilateral, desvio lateral da cabeça para a direita, pupilas dilatadas, apatia e vasos episclerais congestos. Em um dia os sinais progrediram para opistótono, decúbito lateral, cegueira parcial e movimentos de pedalagem. Um dia antes de morrer apresentou miose. Macroscopicamente havia um abscesso de aproximadamente $1 \mathrm{~cm}$ no ouvido médio direito. Histologicamente havia um infiltrado inflamatório neutrofilico na região do fascículo tegmentar do tálamo e colículo rostral, com áreas de hemorragia e necrose. Na região do fascículo longitudinal medial observou-se um infiltrado neutrofilico extenso, com infiltrado inflamatório perivascular linfocitário.

\section{Malformação}

Um ovino, macho, com 3 meses de idade foi trazido ao HV por estar há 15 dias em decúbito permanente. Este animal apresentou discreta dificuldade de locomoção ao nascer, que se agravou com o tempo, até que o mesmo não conseguia mais andar, ficando constantemente em decúbito lateral. $\mathrm{O}$ animal apresentava ainda ataxia quando colocado em estação. Na necropsia observaram-se lordose da coluna cervical e encurtamento do ligamento nucal, com compressão da medula.

\section{Linfossarcoma linfoblástico}

Linfossarcoma linfoblástico foi diagnosticado em 1 caprino, fêmea com 2 anos de idade. Este animal foi trazido ao HV com 
histórico clínico de que há uma semana apresentava progressiva dificuldade de locomoção e debilidade dos membros pélvicos e torácicos. O animal foi sacrificado e na necropsia observou-se, no canal medular, uma massa tumoral esbranquiçada e homogênea de $0,5 \mathrm{~cm}$ de espessura localizada no espaço epidural entre a sétima vértebra cervical e a segunda torácica. Na porção proximal da primeira costela, próximo a articulação costovertebral, notouse uma nodulação arredondada com $10 \mathrm{~cm}$ de diâmetro, que ao corte mostrava-se com as características semelhantes à massa observada no espaço epidural. 0 exame histológico revelou uma massa composta por extensa, homogênea e densa quantidade de células mononucleares com grandes núcleos, um escasso citoplasma eosinofilico e moderadas figuras de mitose atípicas.

\section{Meduloblastoma}

Um ovino macho com 11 meses de idade foi trazido ao HV por apresentar sinais progressivos de andar em círculos, incoordenação motora e cabeça baixa e inclinada para a esquerda. Os achados macroscópicos consistiram de uma assimetria do hemisfério direito do cérebro, com presença de uma massa de aspecto firme e coloração branco-amarelada, medindo aproximadamente $5 \mathrm{~cm}$ de comprimento, localizada na parte anterior do cerebelo e acima do tronco encefálico, que se estendia até o cérebro. Microscopicamente, a massa apresentava numerosas células com núcleos arredondados, cromatina proeminente e citoplasma pouco definido e arranjadas em mantos ou feixes amplos formando pseudorosetas, características dos meduloblastomas.

\section{Necrose simétrica focal}

Um ovino, macho, com 7 meses de idade foi levado ao HV por apresentar anorexia, decúbito permanente, salivação excessiva, pescoço virado para o lado e movimentos de pedalagem. Segundo o proprietário o animal fora levado do campo para a cidade aparentemente normal no dia anterior. Macroscopicamente não havia relato de alterações, mas a microscopia revelou áreas de degeneração e necrose nos corpos geniculatos lateral e medial e na substância nigra, com necrose neuronal, presença de alguns esferóides axonais, algumas áreas de hemorragia e discreto infiltrado de macrófagos. Uma lesão semelhante foi vista no tálamo e hipocampo. Apesar de ter sido examinado um só lado do encéfalo foi realizado diagnóstico de necrose simétrica focal. $O$ outro lado do encéfalo tinha sido encaminhado para diagnóstico de raiva.

\section{Casos sem diagnóstico}

Encefalomielite não supurativa foi observada em um ovino apresentando anorexia, paralisia dos membros pélvicos e decúbito. De um lote de 120 animais da mesma propriedade, 6 já haviam morrido com os mesmos sinais, e havia relato de morte de animais no ano anterior com o mesmo quadro clínico. Apesar da suspeita de raiva o material foi negativo nas provas de imunofluorescência e inoculação de camundongos e na histologia não foram observados corpúsculos de inclusão.

Leptomeningite não supurativa foi observada em uma cabra com um ano de idade proveniente de um rebanho de 500 caprinos, dos quais adoeceram e morreram 2 fêmeas. $\mathrm{O}$ material foi negativo para raiva.
Em abril de 2003, dois caprinos (A e B), fêmeas, SRD, provenientes do município de Santa Terezinha, Paraíba, foram levados ao HV por se apresentarem em decúbito lateral, com opistótono, nistagmo, espasticidade, salivação, movimentos de pedalagem e tremores musculares. Na necropsia do Caprino A observou-se uma grande quantidade de Haemonchus spp no abomaso, pulmão direito com consolidação dos lobos cranial e médio, com presença de pus e linfonodos com pus na região mediastínica. Histologicamente, os dois animais apresentavam meningite histiocítica discreta difusa, com presença de alguns eosinófilos. No Caprino A havia ainda, no gânglio do nervo trigêmeo, uma neurite e gânglioneurite eosinofílica, multifocal acentuada, com presença de vários microabscessos eosinofílicos e um acentuado infiltrado mononuclear. $\mathrm{O}$ pulmão do Caprino B apresentava um acentuado infiltrado mononuclear, infiltrado eosinofílico discreto, com necrose intersticial e fibrose, além de vários microabscessos eosinofílicos.

Um caprino, fêmea, com 7 meses de idade, foi levada ao HV por apresentar depressão, ataxia, cegueira central, hipermetria, diminuição do tônus da língua e deficiência proprioceptiva. $\mathrm{O}$ diagnóstico clínico foi de PEM e o animal foi tratado com vitamina $B_{1}$, mas acabou morrendo 2 dias depois. Ao ser realizada a necropsia a carcaça estava autolisada e não foi possível realizar estudo histológico.

\section{DISCUSSÃO}

Os resultados deste trabalho mostram que as doenças mais freqüentemente diagnosticadas no semi-árido foram abscessos no sistema nervoso central, seguidos por tétano, raiva e intoxicação por Ipomoea asarifolia.

Alta frequiência de abscessos e outras lesões supurativas no SNC foi descrita no Nordeste em um trabalho no qual, de 18 casos em que houve isolamento da bactéria, 3 foram causados por Corynebacterium pseudotuberculosis (Santa Rosa \& Santa Rosa 1999). No presente estudo somente foi realizada cultura de um abscesso, com isolamento de C. pseudotuberculosis. Considerando a alta frequiência de linfadenite caseosa no nordeste (Unanian et al. 1985) e os achados de abscessos em outros órgãos na maioria dos casos, é provável que a maior parte dos abscessos tenham sido provocados por C. pseudotuberculosis. Em um caso havia abscessos na veia umbilical e no figado, tratando-se, aparentemente, de uma infecção neonatal por via umbilical.

$O$ tétano é também uma doença freqüente, principalmente em caprinos, no entanto em 9 diagnósticos tratava-se de casos individuais, ocorrendo somente um surto, no qual vários animais foram afetados. A doença afeta animais de diversas idades e a adoção de medidas higiênicas na realização das práticas de castração e descorna poderá contribuir para a profilaxia da enfermidade, já que em muitos dos casos estudados a doença surgiu após a realização de algum desses procedimentos. A possibilidade de vacinação de forma sistemática como recomendada em eqüinos (Radostits et al. 2002) poderia ser utilizada, pelo menos em rebanhos onde a doença tenha ocorrido anteriormente.

Raiva foi a terceira doença mais freqüente, chamando a atenção para a necessidade da vacinação sistemática dos rebanhos 
nas áreas endêmicas, pois apesar da doença ser menos freqüente do que em bovinos (Lima et al. 2005a) causa perdas econômicas importantes. Além disso, na Paraíba e outras regiões do semiárido a caprinovinocultura vêm substituindo a bovinocultura, o que deve aumentar também a frequiência de ataque de morcegos a ovinos e caprinos.

A intoxicação por Ipomoea asarifolia é uma doença freqüente no semi-árido, mas a maioria dos animais acometidos se recupera após serem retirados das pastagens, nas quais a planta ocorre (Riet-Correa et al. 2003). Neste trabalho foram incluídos somente os casos que morreram, não sendo considerados aqueles que deram entrada no HV e se recuperaram. Todos os surtos ocorreram em animais jovens e na maioria ovinos, confirmando as informações de Riet-Correa et al. (2006) e Silva et al. (2006). Chama à atenção a observação de lesões histológicas no cerebelo de ovinos com sinais clínicos cerebelares, aparentemente irreversíveis. Esferóides axonais semelhantes aos observados nestes casos de intoxicação por I. asarifolia foram descritas em outras doenças tremorgênicas (Summers et al. 1995), e nas intoxicações por Claviceps paspali (Riet-Correa et al. 1983) e Lolium perenne (Mason 1968). Os vacúolos observados na camada granular do cerebelo no Ovino 1 representam, aparentemente, o desaparecimento dos axônios degenerados observados no Ovino 5 .

Quatro diagnósticos de listeriose foram realizados, com base nas lesões histológicas características (Summers et al. 1995), sendo 3 de casos esporádicos e um surto que afetou 6 caprinos em um rebanho de aproximadamente 300 animais. A listeriose é uma doença aparentemente pouco freqüiente no Brasil, ocorrendo geralmente casos esporádicos em bovinos, bubalinos, ovinos e caprinos, preferentemente durante o inverno e primavera (Schild 2001, Hofer \& Dos Reis 2004, Rissi et al. 2006), nas regiões sul e sudeste. Neste trabalho, o diagnóstico de 4 surtos, que ocorreram no final do período chuvoso e início do período seco sugere que a doença pode ser mais importante no semiárido do que em outras regiões do País.

A observação de somente um surto de intoxicação por Ipomoea carnea subsp. fistulosa sugere que esta não é uma intoxicação importante na região, apesar da planta ser freqüentemente encontrada, principalmente nas margens de açudes (Riet-Correa 2006).

Intoxicação por outras espécies de Ipomoea (I. riedelli e $I$. sericophylla) e por outras plantas que causam doenças do SNC, como Prosopis juliflora em caprinos e Crotalaria retusa em ovinos, têm sido relatadas no semi-árido (Lima et al. 2004, 2005a,b, Dantas et al. 2004, Barbosa et al. 2006).

Casos de polioencefalomalacia são mais freqüientes que os observados no Quadro 1, uma vez que não foram incluídos os casos atendidos no HV que se recuperaram após o tratamento. No surto apresentado neste trabalho os ovinos recebiam uma alimentação rica em concentrados e foram submetidos a uma mudança na alimentação 5 dias antes do surgimento do surto, com adição de torta de babaçu à dieta. Sabe-se que alterações na alimentação que promovam alteração da flora ruminal e dietas ricas em grãos podem levar ao surgimento de PEM (Summers et al. 1995), o que provavelmente aconteceu neste caso.

Dois surtos de ataxia enzoótica foram diagnosticados du- rante o período estudado. Outro surto tinha sido diagnosticado em 1998 na Paraíba no município de Campina Grande (RietCorrea et al. 2003). A ocorrência da enfermidade em 3 diferentes municípios do semi-árido paraibano sugere que essa pode ser uma carência freqüente na região, devendo, portanto recomendar-se a suplementação com cobre de animais a pastejo. A enfermidade foi diagnosticada na década de $60 \mathrm{em}$ ovinos no Estado do Piauí (Tokarnia et al. 1966) e em caprinos e ovinos em Pernambuco, nos anos de 2001 e 2002 (Santos et al. 2006).

Um caso isolado e um surto de toxemia da prenhez foram observados, sendo que o surto afetou um rebanho de cabras no início da seca que estavam com um escore corporal baixo e na fase final da gestação. A observação deste surto evidencia que a toxemia da prenhez, no semi-árido, alem de afetar animais gordos, quando submetidos a uma restrição alimentar, pode afetar, também, animais magros em casos de mudança ou restrição alimentar, como citado por Smith \& Sherman (1994).

Com base nas lesões histológicas características (Riet-Correa 2001) foi diagnosticado um caso de necrose simétrica focal. Esta doença é uma forma subaguda da enterotoxemia por Clostridium perfringens tipo D (Riet-Correa 2001). Durante o período de realização deste estudo foram diagnosticados, também, 5 casos da forma hiperaguda da doença, sendo 4 em caprinos e 1 em ovino (Dados não publicados), o que sugere a importância da doença e da vacinação dos rebanhos no semi-árido.

Outras doenças diagnosticadas com menor frequiência foram tumores, traumatismos, malformação, meningite e encefalite devido a otite. Com relação a esta última provavelmente tenha ocorrido em consequiência de otite parasitária, doença freqüente no Brasil, causada por ácaros do conduto auditivo externo, principalmente Psoroptes ovis em ovinos e Psoroptes cuniculi em caprinos (Berne \& Farias 2001).

Casos de malformação envolvendo o SNC em cordeiros e cabritos no período perinatal (1-28 dias de idade) têm sido relatados no semi-árido (Medeiros et al. 2005, Nóbrega Jr et al. 2005). Animais que sobrevivem por mais tempo, como o citado neste trabalho, geralmente apresentam malformação de outros órgãos, como membros torácicos, mandíbula, focinho e olhos. No semi-árido essas malformações estão associadas à ingestão de jurema preta (Mimosa tenuiflora) pelas fêmeas gestantes (RietCorrea et al. 2006).

Neoplasias do SNC, como meduloblasoma e linfossarcoma são relatados em bezerros, cães e seres humanos (Jones et al. 2000), e esporadicamente em gatos e suínos (Summers et al. 1995).

Os resultados deste trabalho demonstram que o manejo inadequado pode causar perdas no rebanho caprino e ovino do semi-árido, já que a maioria das doenças encontradas, como abscessos, tétano, polioencefalomalacia, ataxia enzoótica e toxemia da prenhez poderiam ser facilmente evitadas com manejo sanitário e alimentar apropriados. Outro fator observado neste trabalho é a importância das plantas tóxicas para a região, já que $14,28 \%$ dos diagnósticos realizados foram de intoxicação por plantas, as quais são frequentemente ingeridas por pequenos ruminantes, especialmente na época de estiagem, quando há escassez de forragem. 
Agradecimentos.- Este projeto foi financiado pela Fundação de Amparo à Pesquisa da Paraíba/ Ministério da Ciência e Tecnologia (Edital 004/03 FAPESQ-MCT), e pelo Programa Institutos do Milênio (Proc. 420012/2005-2).

\section{REFERÊNCIAS}

Barbosa R.C., Riet-Correa F., Medeiros R.M.T., Lima E.F., Barros S.S., Gimeno E.J., Molyneux R.J. \& Gardner D.R. 2006. Intoxication by Ipomoea sericophylla and Ipomoea riedelli in goats in the state of Paraíba, Northeastern Brazil. Toxicon 47:371-379.

Berne M.E. \& Farias N.A. 2001. Sarna, p.52-59. In: Riet-Correa F., Schild A.L., Mendez M.C. \& Lemos R.A.A. (ed.), Doenças de Ruminantes e Eqüinos. Vol. 2. $2^{\underline{a}}$ ed. Varela Editora, São Paulo.

Dantas A.F.M., Nobre, V.M.T., Riet-Correa F., Tabosa I.M., Júnior G.S., Medeiros J.M., Silva, R.M.N., Silva E.M.N., Anjos B.L. \& Medeiros J.K.D. 2004. Intoxicação crônica espontânea por Crotalaria retusa (Fabaceae) em ovinos na região do semi-árido paraibano, Brasil. Pesq. Vet. Bras. 24(Supl.):18-19.

Hofer E. \& Dos Reis C.M.F. 2004. Espécies e sorovares de Listeria isolados de animais doentes e portadores no Brasil. Pesq. Vet. Bras. 25(2):79-83.

Jones T.C., Hunt R.D., King N.W. 2000. Patologia Veterinária. 1a ed. Editora Manole, São Paulo. 1400p.

Lima E.F., Riet-Correa F., Amorim S.L. \& Sucupira Jr G. 2004. Intoxicação por favas de Prosopis juliflora (algaroba) em caprinos no Nordeste do Brasil. Pesq. Vet. Bras. 24(Supl.):36-37.

Lima E.F., Riet-Correa F., Castro R.S., Gomes A.A.B. \& Lima F.S. 2005a. Sinais clínicos, distribuição das lesões no sistema nervoso e epidemiologia da raiva em herbívoros na região Nordeste do Brasil. Pesq. Vet. Bras. 25(4):250264

Lima E.F., Riet-Correa F., Tabosa I.M., Dantas A.F.M. \& Sucupira Jr G. 2005b. Polioencefalomalacia em caprinos e ovinos na região semi-árida do Nordeste do Brasil. Pesq. Vet. Bras. 25(1):9-14.

Mason R.W. 1968. Axis cilinder degeneration associated with Ryegrass staggers in sheep and cattle. Aust. Vet. J. 44:428.

Medeiros J.M., Tabosa I.M., Simões S.V.D., Nóbrega Jr J.E., Vasconcelos J.S., Riet-Correa F. 2005. Mortalidade perinatal em cabritos no semi-árido paraibano. Pesq. Vet. Bras. 25(4):201-206.

Nóbrega Jr J.E., Riet-Correa F., Nóbrega R.S., Medeiros J.M., Vasconcelos J.S., Simões S.V.D. \& Tabosa I.M. 2005. Mortalidade perinatal de cordeiros no semi-árido da Paraíba. Pesq. Vet. Bras. 25(3):171-178.

Radostits O.M., Gay C.C., Blood D.C. \& Hinchcliff K.W. 2002. Clínica Veterinária. Um Tratado de Doenças dos Bovinos, Ovinos, Suínos, Caprinos e Eqüinos. 9a ed. Guanabara Koogan, Rio de Janeiro. 1737p.
Ribeiro S.D.A. 1997. Caprinocultura, Criação Racional de Caprinos. Nobel, São Paulo. 318p.

Riet-Correa F., Schild A.L., Mendez M.C., Tavares A.S. \& Rodrigues J.O. 1983. Intoxicação por Claviceps paspali em bovinos no Rio Grande do Sul. Pesq. Vet. Bras. 3:59-65.

Riet-Correa F. 2001. Enterotoxemia e necrose simétrica focal, p.238-241. In: Riet-Correa F., Schild A.L., Mendez M.C. \& Lemos R.A.A. (ed.), Doenças de Ruminantes e Eqüinos. Vol. 1. $2^{\underline{a}}$ ed. Varela Editora, São Paulo.

Riet-Correa F., Tabosa I.M., Azevedo E.O., Medeiros R.M., Simões S.V.D., Dantas A.F., Alves C.J., Nobre V.M.T., Athayde A.C., Gomes A.A. \& Lima E.F. 2003. Doença dos ruminantes e eqüinos no semi-árido da Paraíba. Semi-árido em Foco 1:4-111.

Riet-Correa F., Medeiros R.M.T. \& Dantas A.F.M. 2006. Plantas Tóxicas da Paraíba. Centro de Saúde e Tecnologia Rural, Patos, PB. Ed. SEBRAE/PB. 58p.

Rissi D.R., Rech R.R., Barros R.R., Kommers G.D., Langohr I.M., Pierezan F. \& Barros C.S.L. 2006. Forma nervosa de listeriose em caprinos. Pesq. Vet. Bras. 26(1):14-20.

Santa Rosa J. \& Santa Rosa M.G. 1999. Inflamações supuradas e gra-nulomatosas no sistema nervoso de caprinos. Ciênc. Vet. Trop. 2(2):108-114.

Santos N.V.M., Sarkis J.E.S., Guerra J.L., Maiorka P.C., Hortelani M.A., Silva F.F., Ortolani E.L. 2006. Avaliação epidemiológica, clínica, anatomo-patológica e etiológica de surtos de ataxia em cabritos e cordeiros. Ciência Rural, Santa Maria, 36(4):1207-1213.

Schild A.L. 2001. Listeriose, p.288-292. In: Riet-Correa F., Schild A.L., Méndez M.C. \& Lemos R.A.A (ed.), Doenças de Ruminantes e Eqüinos. Vol. 1. $2^{2}$ ed. Varela Editora, São Paulo.

Silva D.M., Riet-Correa F., Medeiros R.M.T. \& Oliveira O.F. 2006. Plantas tóxicas para ruminantes no Seridó Ocidental e Oriental do Rio Grande do Norte. Pesq. Vet. Bras. 26(4):223-236.

Smith M.C. \& Sherman D.M. 1994. Goat Medicine. Lea and Febiger, Philadelphia. 620 p.

Summers B.A., Cummings J.F. \& de Lahunta A. 1995. Veterinary Neuro-pathology. Mosby-Year Book, St Louis. 527p.

Tokarnia C.H., Döbereiner J., Canella C.F.C. \& Guimarães G.A. 1966. Ataxia enzoótica em cordeiros no Piauí. Pesq. Agrop. Bras., Seção Veterinária. 1:375382.

Unanian M.M., Silva A.E.D.F. \& Pant K.P. 1985. Abscesses and caseous lymphadenitis in goats in tropical semi-arid North-East Brazil. Trop. Anim. Hlth Prod. 17:57-62. 